\title{
Life quality for ostomized patients: a perspective in the health and nursing care process
}

\author{
Cristilene A. Kimura ${ }^{* 1,2}$, Dirce B. Guilhem ${ }^{1,3}$, Ivone Kamada ${ }^{1}$, Breno S. Abreu ${ }^{1,2,4}$, Karina R. Modesto ${ }^{1,2,5}$, Jonas R. \\ Gonçalves ${ }^{2,4,6}$ \\ ${ }^{1}$ The University of Brasilia (UnB), Brasilia, Brazil \\ ${ }^{2}$ Sena Aires Science and Education College (Facesa)-Valparaíso de Goiás (GO), Brazil \\ ${ }^{3}$ National Council of Technological and Scientific Development (CNPq), Brasilia, Brazil \\ ${ }^{4}$ Universidade Paulista, Brasília (DF), Brazil \\ ${ }^{5}$ Genomic Science and Biotechnology at UCB, Brazil \\ ${ }^{6}$ Political Sciences at Euroamerican College (Unieuro), Brasília (DF), Brazil
}

Received: September 1, 2016

DOI: $10.5430 /$ jnep.v7n4p22
Accepted: September 28, $2016 \quad$ Online Published: November 20, 2016

URL: http://dx.doi.org/10.5430/jnep.v7n4p22

\begin{abstract}
Evidence shows that there is association between the quality of life (QoL) of ostomized patients and the results of WHOQOL-bref questionnaire. Mensurable knowledge regarding facets and dimension of the mentioned questionnaire is highly valuable for guidance involving the multidisciplinary crew for nursing care, taken into consideration that specialized care has major influence on the QoL scores. To better assess which of these facets are strongly correlated to tue questionnaire dimensions targeting its identification and the development of internal guidelines take advantage of such information aiming to improve QoL on the one hundred and six patients served by the Ambulatory Care Program for ostomy patients in the Federal District Health Secretariat, Brazil. The questionnaire scores where correlated to the several dimensions in order to pinpoint which of those has major contribution on patients QoL, by generating correlation coefficient (square $r$ ) and $t$-student tests. The facets of Physical Domains, Social Affairs and Environment are correlated with the mean score, resulting in statistically significant associations $(p<.0001)$. The awareness about ostomy patients' reality may result in effective comprehensive health care of the person with ostomy, and the consequent improvement of their QoL, resulting in a process of care in health nursing, which may impact the patient's the ability to socialize and interact, reducing the impact of depression events and its consequences as well as improving the general well being of the patient in terms of self body image and self esteem as required by the Integral health care policy. Thus, the nursing care process becomes an active and continuous act demanding special actions and behaviors targeting the improvement of human potentials, focusing on enhancing the dignity of the ostomized person, for which the nursing care process is fundamental for recovering the QoL scores to better and higher levels.
\end{abstract}

Key Words: Quality of life, Ostomy, Nursing, Comprehensive health care, Integral health care

\section{INTRODUCTION}

The World Health Organization defines quality of life (QoL) as "the individual's perception of their position in life concerning the cultural context and the values system they live in, related to their aims, aspirations, standards and concerns". ${ }^{[1]}$ In this sense, QoL is a broad and comprehensive notion, complexically affected by one's physical health; in other words, it is a multidimensional, dynamic, subjective, individual,

*Correspondence: Cristilene A. Kimura; Email: cris.akiko7@ gmail.com; Address: The University of Brasilia (UnB), Brasilia, Brazil. 
and complex concept, which aims to interconnect physical, social, spiritual and environmental aspects. ${ }^{[2,3]}$

On a subjective perspective, QoL assessment depends directly on the individual's personal evaluation. Concerning multidimensional aspect, it is important to assess one's physical wealth, functional capacity, and their psychological and social health. ${ }^{[2,3]}$ This way, and defining QoL as one of human life dimensions, its evaluation acquires crucial importance, especially concerning the intestinal ostomized individual's health and nursing care process. ${ }^{[4]}$

An intestinal ostomized person suffers from changes in their body image, low self-esteem, expectations of rejection and changes in their daily routine, which may bring difficulty on their process to accept a new and still unknown reality, undermining QoL. ${ }^{[3,5,6]}$ Evidence suggests that non ostomized people present higher QoL scores when compared to ostomized people. Such reduction on the scores are related to the impact of ostomy surgery in terms of body image, socialization, self-esteem and the stigma, generating severe impact on the Social, Physical, Psychological, Spiritual and Enviromental domains. ${ }^{[2,3,5,14]}$ However, the characterization of the QoL profile for ostomized patients on Brazilian Programs is to be consolided. However, the recent data suggests that the main impact of ostomy on QoL is observed regardless of causes of ostomy, the emergency or scheduled procedure, having no significant differences on QoL reduction after the ostomy. ${ }^{[3,5,14,16,23,26]}$

Furthermore, in the intestinal ostomized point of view, the meaning of having their body distorted, and the anguish caused by their new lifestyle due to the use of collectors, undervalues their social and personal relationships. Thus, with decayed body image and low self- esteem, ostomized people take an attitude of social distancing and isolation, undermining their QoL. ${ }^{[3]}$

This way, a relevant challenge for broad health assistance destined to intestinal ostomized is imposed, as ostomized QoL means reaching the highest level of wealth and autonomy. ${ }^{[3,4]}$ Thus, education about health is imperative and essential to the caring process in health and nursing fields; resulting on high quality assistance, since the nurse, more than a caretaker is an educator, not only for other members in the nursing crew, but also for the patient, their relatives and informal caretaker. This brings the development of practical procedures for people's QoL.

Based on the above considerations, it is necessary to understand people's perception on issues concerning and influencing their lives and the impact of the confection of an ostomy on QoL. The profiling of major impact of an ostomy on QoL

Published by Sciedu Press of ostomized patients, regardless of the temporary or permanent status, is of great value in terms of guiding the nursing crew on reaching the QoL improvement. There are several QoL measuring instruments, but one out of the most used is the World Health Organization Quality of Life-100 (WHOQOL-100) and its short version, the WHOQOL-bref. ${ }^{[7]}$ The instrument presents a transcultural approach and works on three important aspects: subjectivity (an individual perception about their own life); multidimensionality (inclusion of several dimensions in life); and the presence of both positive and negative evaluation elements. ${ }^{[1,7]}$ The questionnaire is divided into facets comprising four dimensions: physical, psychological, social relationships, and environment. ${ }^{[7]}$

Based on this concept, the aim of this study was to analyze the relation between these facets and their respective dimensions in QoL for intestinal ostomized people served by the Ostomized Patient Program of Health Secretariat of the Federal District, Brazil, on the perspective of the nursing and health care process. Being the nursing care crew the most available health professionals for ostomized people in Brazilian Unified Health Care, the adoption of those relations on determining the guidelines may highly improve the recovery of QoL levels on ostomized patients, as several evidences confirms.

\section{MATERIALS AND METHODS}

\subsection{Methodology}

This study was carried out on an epidemiological basis, presenting transversal and descriptive design and analytical nature. Participants included in this research belong to a group of intestinal ostomized people being enrolled on the Ostomized Patient Program of Health Secretariat of the Federal District. These patients were undergoing ostomy surgeries for several causes and were asked to take part in the survey. After locating the potential centers for patient approaching based on will to take part on the survey, the Free Informed Consent Form was administered followed by the aforementioned questionnaire by the principal investigator, individually in order not to taint one's self perception of QoL impact of an ostomy. Observation and measuring of factors of interest were carried out simultaneously, providing a statistic portrait of events on that specific moment.

The research methods protocol was approved by the Ethics in Research Commitee of the Health Science Teaching and Research Bureau of Health Secretariat of the Federal District, Brazil, registered under n. 418/200. People who agreed on participating signed up a Consent and Awareness Term, after receiving detailed explanation about the proposed aims and procedures. In accordance with what is stated by Brazilian Regulation for research involving human beings, the volun- 
teers' anonymity, as well as discretion about the data origin is guaranteed. ${ }^{[8]}$

\subsection{Case-by-case basis}

The study sample group was gathered by convenience, considering patients spontaneous enrollment to take part of the study. One hundred and six intestinal ostomized patients enrolled at the Ostomized Patient Program of Health Secretariat of the Federal District, Brazil, were included.

As study inclusion criteria, we selected patients with intestinal ostomy surgical intervention, aged 20 or above. Children, adolescents, patients confined to bed, patients with physical handicaps and ostomy patients due to colorectal cancer, as well as those who did not agree to participate on the present study were excluded from the surveyed group. Ostomized pregnant women and nursing mothers were excluded due to known reduction of QoL scores perceived partly as an outcome of the motherhood associated to ostomy related issues, avoiding a significant bias.

\subsection{Data collection}

Data was collected from March 2010 to August 2012. Two data collection instruments were used: a social, clinical and demographic questionnaire, and valid Portuguese version of the WHOQOL-bref. It has 26 items: two general questions refer to patients' perception on their QoL, and their satisfaction with their health. The four dimensions (Physical, Psychological, Social Relationships, and Environment) and their respective facets display both objective and subjective assessment aspects. Answers to questions were obtained by Likert scale, ranging from 1 to 5. Answers varied concerning intensity (none - extremely), capacity (none - completely), frequency (never-always), and evaluation (very dissatisfied very satisfied; and really bad - very good). ${ }^{[7,9]}$

\subsection{Statistical analysis}

A descriptive statistical analysis of the social, clinical and demographical questionnaire was carried out. Data from WHOQOL-bref questionnaire were analyzed by calculating average, standard deviation, proportions and inferential analysis, employing the following statistical procedures: confidence interval of $95 \%, t$-student-test with normal distribution, Mann-Whitney test with asymmetrical distribution, and Pearson linear correlation coefficient test.

A statistical analysis was carried out on the SPSS software (Statistical Package of the Social Sciences, SPSS Inc, Chicago, EUA) for Windows version 20.0, according to World Health Organization guideline. Accepted statistic relevance was of $5 \%$.

\section{RESUltS}

Table 1 presents an outline on study participants' social and demographical features. The age average observed was 42.54 \pm 11.47 years, where most participants are aged between 20 to 29 years old $34 \%(n=36)$. Regarding gender, $68.8 \%$ of this group $(n=73)$ are male patients.

The predominant religion verified was catholicism 54\% (n $=58)$, followed by protestants $25.4 \%(\mathrm{n}=27)$, considering that $73.6 \%(n=78)$ of all participants claimed to belong to some religion.

Regarding other social and demographical variables, as for marital status, most participants are married 53.8\% $(n=57)$. Concerning formal education, $54.8 \%(n=58)$ out of participants had finished high school. Regarding labor status, the majority of the group $50 \%(n=53)$ was retired. The monthly income most indicated by participants $67.9 \%(n=72)$ ranged between 1 to 3 times Brazilian minimum wage.

Considering participants clinical features, as described in Table 2, ostomized time variable indicated a predominance between $>12$ months and $\leq 60$ months, corresponding to $47.1 \%(n=50)$ of participants. Regarding the kind of intestinal ostomy, $52.8 \%(\mathrm{n}=56)$ of them had permanent ostomies. Concerning comorbidities, $30.1 \%(n=32)$ had arterial hypertension, and $17.9 \%(n=19)$ had Diabetes Mellitus. Besides, $39.7 \%(n=42)$ of participants were smokers. Such information is important as it has impacts on the demands of health services in the Unified Health Care System, and as such, has major potential complications. Present data shows that the most important aspects of comorbidities are related to Chagas' disease, Arterial Hypertension and Diabetes, being able to increase mobi-mortality and induce reductions on QoL scores on such patients. Intestinal bowel diseases are related to several aspects, including smoking habits. Also, for Fournier's disease, the most correlated co-morbidities are diabetes, malnutrition and obesity, among others. ${ }^{[4,5]}$

As shown in Table 3, the following causes for intestinal ostomy surgery are mentioned: abdominoperineal traumas, including motor vehicle accidents (MVA) and bladed and firearm weapons $46.3 \%(n=49)$, inflammatory bowel disease $17.9 \%(n=19)$, Chagas' disease $15.1 \%(n=16)$, diverticular disease $11.3 \%(n=12)$, and Fournier Syndrome 9.4\% $(n=$ 10). Regarding abdominoperineal traumas, $20.8 \%(n=22)$ are related to MVA's, followed by firearm perforation $18.9 \%$ $(n=20)$ and bladed weapon perforation $6.6 \%(n=7)$.

The results shown in Table 4 presented statistically significant difference on average scores to the dimensions: physical, psychological, social relations, and environment, and for QoL in general, resulting on statistical relevance $(p<.0001)$. 
Table 1. Intestinal ostomized patients sample according to social and demographic features. Brasilia, Federal District, Brazil, 2016

\begin{tabular}{|c|c|c|}
\hline \multirow{2}{*}{ Variables } & \multicolumn{2}{|c|}{ Ostomized patients } \\
\hline & $\mathbf{N}$ & $\%$ \\
\hline \multicolumn{3}{|l|}{ Gender } \\
\hline Female & 33 & 31.2 \\
\hline Male & 73 & 68.8 \\
\hline Total & 106 & 100 \\
\hline \multicolumn{3}{|l|}{ Age range } \\
\hline $20-30$ & 36 & 34 \\
\hline $30-40$ & 28 & 26.4 \\
\hline $40-50$ & 14 & 13.2 \\
\hline $50-60$ & 16 & 15.1 \\
\hline $60-70$ & 9 & 8.4 \\
\hline $80-90$ & 3 & 2.9 \\
\hline Total & 106 & 100 \\
\hline \multicolumn{3}{|l|}{ Religion } \\
\hline Catholic & 58 & 54 \\
\hline Protestant & 27 & 25.4 \\
\hline Spiritist & 16 & 15 \\
\hline Others & 5 & 5.6 \\
\hline Total & 106 & 100 \\
\hline \multicolumn{3}{|l|}{ Religous practice } \\
\hline Yes & 78 & 73.6 \\
\hline No & 28 & 26.4 \\
\hline Total & 106 & 100 \\
\hline \multicolumn{3}{|l|}{ Marital status } \\
\hline Married & 57 & 53.8 \\
\hline Stable Union & 16 & 15.1 \\
\hline Divorced & 18 & 17 \\
\hline Widow(er) & 4 & 3.8 \\
\hline Single & 11 & 10.3 \\
\hline Total & 106 & 100 \\
\hline \multicolumn{3}{|l|}{ Formal education } \\
\hline None to Junior High & 26 & 24.5 \\
\hline High School & 58 & 54.8 \\
\hline Graduation & 22 & 20.7 \\
\hline Total & 106 & 100 \\
\hline \multicolumn{3}{|l|}{ Labor status } \\
\hline Retired & 53 & 50.0 \\
\hline Medical Leave & 28 & 26.4 \\
\hline Working & 10 & 9.5 \\
\hline Unemployed & 15 & 14.1 \\
\hline Total & 106 & 100 \\
\hline \multicolumn{3}{|l|}{ Income } \\
\hline$<1$ to $3 \mathrm{MW}$ & 72 & 67.9 \\
\hline 4 to $5 \mathrm{MW}$ & 21 & 19.9 \\
\hline$>6 \mathrm{MW}$ & 13 & 12.2 \\
\hline Total & 106 & 100 \\
\hline
\end{tabular}

Starting from results obtained, we tried to identify facets strongly connected to QoL in each one of WHOQOL-bref dimensions, by relating each question composing each dimension with its average score, in order to make possible the group assessment of such facets, as shown in Tables 5-8.

From data shown in Table 5, it is possible to infer that the intestinal ostomized group significantly associated most facets on physical dimension; remarkably strong correlation was observed to the facets: daily life activities, labor capacity, sleep and rest.

Table 2. Intestinal ostomized patients sample according to clinical features. Brasilia, Federal District, Brazil, 2016

\begin{tabular}{|c|c|c|}
\hline \multirow{2}{*}{ Variables } & \multicolumn{2}{|c|}{ Ostomized patients } \\
\hline & $\mathbf{N}$ & $\%$ \\
\hline \multicolumn{3}{|l|}{ Ostomy period (in months) } \\
\hline$\leq 12$ months & 26 & 24.6 \\
\hline$>12$ months and $\leq 60$ months & 50 & 47.1 \\
\hline$>60$ months & 30 & 28.3 \\
\hline Total & 106 & 100 \\
\hline \multicolumn{3}{|l|}{ Kind of intestinal ostomy } \\
\hline Definitiveo & 56 & 52.8 \\
\hline Temporary & 50 & 47.2 \\
\hline Total & 106 & 100 \\
\hline \multicolumn{3}{|l|}{ Diabetes mellitus } \\
\hline Yes & 19 & 17.9 \\
\hline No & 87 & 82.1 \\
\hline Total & 106 & 100 \\
\hline \multicolumn{3}{|l|}{ Hipertensão arterial } \\
\hline Yes & 32 & 30.1 \\
\hline No & 74 & 69.9 \\
\hline Total & 106 & 100 \\
\hline \multicolumn{3}{|l|}{ Smoker } \\
\hline Yes & 42 & 39.7 \\
\hline No & 64 & 60.3 \\
\hline Total & 106 & 100 \\
\hline
\end{tabular}

Table 3. Intestinal ostomized patients sample according to intestinal ostomy reason. Brasilia, Federal District, Brazil, 2016

\begin{tabular}{lll}
\hline \multirow{2}{*}{ Ostomy reason } & \multicolumn{2}{l}{ Ostomized Patients } \\
\cline { 2 - 3 } & $\mathbf{n}$ & $\mathbf{\%}$ \\
\hline Abdominoperineal traumas * & 49 & 46.3 \\
Inflammatory Bowel Diseases & 19 & 17.9 \\
Chagas’ Disease & 16 & 15.1 \\
Diverticular Disease & 12 & 11.3 \\
Fournier Syndrome & 10 & 9.4 \\
Total & 106 & 100 \\
\hline
\end{tabular}

\footnotetext{
*These include Motor Vehicle accident, Perforation from firearms and bladed weapons.
} 
Table 4. WHOQOL- bref average scores for dimensions and QoL for ostomized patients. Brasilia, Federal District, Brazil, 2016

\begin{tabular}{llllll}
\hline Ostomized Patients & & & & & \\
\hline Dimensions & $\mathbf{n}$ & Average & SD & CI 95\% & P \\
\hline Physical & 106 & 12.20 & 1.92 & $11.83-12.57$ & .6389 \\
Psychologocal & 106 & 12.10 & 2.25 & $11.67-12.53$ & .3947 \\
Social Relations & 106 & 12.06 & 2.68 & $11.54-12.58$ & .1266 \\
Environment & 106 & 12.09 & 2.19 & $11.67-12.51$ & .6747 \\
LQ General & 106 & 12.10 & 1.86 & $11.74-12.46$ & .5670 \\
\hline
\end{tabular}

Table 5. Correlation between each question and the Physical Dimension average score for ostomized patients. Brasilia, Federal District, Brazil, 2016

\begin{tabular}{llll}
\hline \multirow{2}{*}{ Questions } & Assessed Facet & \multicolumn{2}{l}{ Ostomized Patients } \\
\cline { 3 - 4 } & & $\boldsymbol{r}$ & $\boldsymbol{p}$ \\
\hline 1 & Pain and discomfort & -0.63 & $<.0001$ \\
2 & Energy and fatigue & 0.51 & $<.0001$ \\
3 & Sleep and rest & -0.72 & $<.0001$ \\
9 & Mobility & -0.64 & $<.0001$ \\
10 & Daily life activities & -0.83 & $<.0001$ \\
11 & Medication or treatment dependence & -0.48 & $<.0001$ \\
12 & Labor Capability & -0.77 & $<.0001$ \\
\hline
\end{tabular}

Data in Table 6 showed that the facet: spiritual- tions dimension, in Table 7, results pointed that the three ity/religion/personal beliefs, was the major association on related facets: personal relationships, sexual activity, and psychological dimension, followed by the facets: body im- social support are strongly related to average score acquired age, appearance, and self-esteem. Whereas on social rela- on the referred dimension, with statistic relevance $(p<.001)$.

Table 6. Correlation between each question and the Psychological Dimension average score for ostomized patients. Brasilia, Federal District, Brazil, 2016

\begin{tabular}{llll}
\hline \multirow{2}{*}{ Questions } & Assessed Facet & \multicolumn{2}{l}{ Ostomized Patients } \\
\cline { 3 - 4 } & & $\boldsymbol{r}$ & $\boldsymbol{p}$ \\
\hline 4 & Positive feelings & 0.31 & .429 \\
5 & Thinking, learning, memory and focus & 0.45 & .578 \\
6 & Self-esteem & -0.74 & $<.0001$ \\
7 & Body image and appearance & -0.77 & $<.0001$ \\
8 & Negative Feelings & -0.51 & $<.0001$ \\
24 & Spirituality/religion/personal beliefs & 0.78 & $<.0001$ \\
\hline
\end{tabular}

Table 7. Correlation between each question and the Social Relations Dimension average score for ostomized patients. Brasilia, Federal District, Brazil, 2016

\begin{tabular}{llll}
\hline \multirow{2}{*}{ Questions } & \multirow{2}{*}{ Assessed Facet } & \multicolumn{2}{c}{ Ostomized Patients } \\
\cline { 3 - 4 } & & $\boldsymbol{r}$ & $\boldsymbol{p}$ \\
\hline 13 & Personal Relationships & -0.74 & $<.0001$ \\
14 & Social support & 0.77 & $<.0001$ \\
15 & Sexual activity & -0.76 & $<.0001$ \\
\hline
\end{tabular}

Data in Table 8 showed weaker correlation values for environment dimension when compared to other dimensions. It is important to mention that only two facets showed relations to the average score acquired on this dimension: availability and quality of social and health care; and opportunity to acquire new skills and access to new information.

\section{Discussion}

The age average of intestinal ostomized patients was $42.54 \pm$ 11.47 years, highlighting the prevailing age ranged between 
20 to 29 years old $34 \%(n=36)$, and 30 to 39 years old $26.4 \%$ $(\mathrm{n}=28)$. These findings confirm previous studies carried out by the Violence and Injury Prevention Department of the World Health Organization, which indicates most car acci- dents affect people between 15 and 44 years old. ${ }^{[10]}$ Some studies still show that the population age group affected by fire gun perforation or melee weapon wound is made by individuals aged between 20 and $40 .^{[11]}$

Table 8. Correlation between each question and the Environment Dimension average score for ostomized patients. Brasilia, Federal District, Brazil, 2016

\begin{tabular}{llll}
\hline \multirow{2}{*}{ Question } & Assessed Facet & \multicolumn{2}{l}{ Ostomized Patients } \\
\cline { 3 - 4 } & & $\boldsymbol{r}$ & $\boldsymbol{p}$ \\
\hline 16 & Physical safety and protection & 0.38 & .009 \\
17 & Home environment & 0.48 & .012 \\
18 & Financial Resources & 0.27 & .003 \\
19 & Social da Health Care: availability and quality & -0.76 & $<.0001$ \\
20 & Opportunities to acquire new info and skills & -0.74 & $<.0001$ \\
21 & Participation, and opportunities of entertainment/leisure & 0.33 & .005 \\
22 & Physical environment: (pollution/noise/traffic/weather) & 0.24 & .002 \\
23 & Transportation & 0.64 & .0013 \\
\hline
\end{tabular}

Among external causes for intestinal ostomies, car accidents due to traffic violence, as well as firegun perforation and melee weapons stabs stand out, as a consequence of greater exposure to urban violence. ${ }^{[4,12]}$ Above all, urban violence is pointed as the most usual cause for the demand for medical emergency services, and it is seen as a factor for the growing number of people with intestinal ostomies. ${ }^{[4]}$ Although such evidences point towards the higher ostomy surgery frequency in males due to violence, such aspects are reproducible on other countries, obviously related also to the level of violence observed among different cultures and countries.

Concerning gender, the number of male patients prevailed, which is in accordance with previous studies, showing that those mostly affected by physical trauma are men of lower social classes and educational levels. The profile raised, along with Brazilian average life expectancy made the Brazilian Statistic and Geography Institute (IBGE) investigate further for details on the number of deaths for external causes, in order to determine the social impact caused by such events. ${ }^{[4,11]}$

The predominant religions observed were the Catholicism $54 \%(\mathrm{n}=58)$, followed by Protestantism 25.4\% ( $\mathrm{n}=27)$, which configures a reflex of Brazilian religious profile, as Brazil is seen as the biggest Catholic country in the world. Religious practice in face of disease may lead to the conception of a spiritual growth wish, as it reminds the human being about their fragility, and their closeness to human finitude. ${ }^{[5]}$

Regarding marital status variable, $53.8 \%(\mathrm{n}=57)$ of the participants were married, and $15.1 \%(n=16)$ were on a stable union. This is an important result because, regardless legal classification, being married represents a supporting factor,

Published by Sciedu Press as married people showed better physical and psychological wealth levels than those who were single, separated or divorced. ${ }^{[3,5]}$

Concerning school degree and family monthly income, it was observed that the group of patients was mainly composed by people with low formal instruction, where $54.8 \%$ ( $\mathrm{n}=$ 58) had only finished high school, which narrows job opportunities and reflects on the low salaries they earned (2.35 Brazilian minimum wage on average). This situation shows that educational level interferes on QoL; in other words, a higher school level has a positive influence on QoL, and economical problems may affect them negatively. ${ }^{[5,13,14]}$

Concerning the variable labor status, there was a prevalence of retired $50 \%(n=53)$ and $26.4 \%(n=28)$ set away from work by Brazilian National Institute of Social Welfare (INSS). It was observed that ostomized people have difficulty to return to labor marked. In general, those who are formally hired prefer to retire definitively, and those who are unemployed are not able to join formal labor market. ${ }^{[?, 3]}$

Regarding the variable intestinal ostomy type, a slight prevalence of permanent ostomy should be remarked, $52.8 \%$ (n $=56)$, in comparison with temporary ones $47.2 \%(\mathrm{n}=50)$. Thus, intestinal ostomy surgery leads to a range of adaptations that have to be done due to changes in life, resulting on an undermining of QoL, regardless if the ostomy is provisory or permanent. ${ }^{[14,16]}$ As a consequence, independent from that previous aspect, an ostomized person has their QoL reduced in several dimensions: physical, psychological, social relations, and environment. 
Concerning comorbidities, a significant percentage of diabetes and arterial hypertension were seen, that is, participants declared to have high blood pressure and diabetes, 30.1\% (n $=32)$, and $17.9 \%(\mathrm{n}=19)$, respectively.

Epidemiologic studies show that diabetes and high blood pressure are commonly associated conditions. The incidence of arterial hypertension is about twice as present in diabetic patients, in comparison with non-diabetic. Besides, hypertension affects $40 \%$ or more out of the diabetic individuals. These studies show that all regions in Brazil had a statistically relevant increase on the standard coefficient for diabetes + hypertension, with a remarkable raise for Middle-Western and Northeastern Regions, which had their standard coefficients both raising from $1.3 \%$ in 1998 to $2.4 \%$ in $2008 .^{[18]}$ Such comorbidities were present prior to the ostomy surgery, however, even on those cases where the patient already had a decrease on QoL scores due to a prior morbidity, the impact of the ostomy surgery is detectable.

Studies estimate a gender and age pattern of prevalence for diabetes, based on 2010 world population, and showed projected numbers to 2030 in several countries, including Brazil. ${ }^{[19]}$ According to these estimates, between 2010 and 2030, the number of diabetic adults from 20-79 in developing countries will raise up to $69 \%$. ${ }^{[18]}$

Frequent association of chronical diseases leads to an expressive demand for health services and medication, predisposing patients to a number of risks. The association of Chagas' disease and other chronical diseases, such as hypertension and diabetes may raise morbidity and mortality, and worsen QoL of those facing this adverse condition. ${ }^{[18]}$

Inflammatory bowel diseases are related to several causes, including, among them, smoking. ${ }^{[19]}$ Out of risk factors for the Fournier Syndrome, some remarkable ones are diabetes mellitus, malnutrition and obesity, among others. ${ }^{[4,20]}$

This study showed that $17.9 \%(n=19)$ of the patients have diabetes, whereas seven ostomized patients are being treated for Fournier Syndrome. Besides, 39.7\% ( $\mathrm{n}=42)$ are smokers, and it was observed that $15.1 \%(n=16)$ out of the ostomized have Inflammatory bowel Diseases.

As identified in the ostomized group, abdominoperineal traumas prevailed in comparison with other intestinal ostomy causes, where most of them were caused by car accidents $20.8 \%(n=22)$, followed by fire gun injuries $18.9 \%(n=20)$ and melee weapon stabs $6.6 \%(n=7), 46.3 \%(n=49)$ in total.

From the 1980's on, there was a raise on external reasons mortality rate, representing the second most common death cause in Brazil. It was observed that most deaths were caused by car accidents and gunshots. This way, accidents and homicides were mostly responsible for this raise. ${ }^{[4,11]}$

Average scores for QoL and its dimensions shown by WHOQOL-bref, Table 4, allow us to find significant statistic difference on average scores for dimensions physical, psychological, social relations and environment, as well as on general QoL average score. Studies about QoL in intestinal ostomized patients point that ostomy implies not only using collector equipment, but a new body image that needs to be re-constructed. This is a subjective and social/collective process at the same time. Such process also implies deep reflection on how to live with an intestinal ostomy, which may affect physical and psychological dimensions, as well as the environment and social relations, undermining QoL. ${ }^{[3,5]}$

Concerning WHOQOL-bref questionnaire, we decided to point, on this study, to the discusion of facets presenting a higher association degree $(r>0.71)$, in other words, those strongly commected to their respective dimensions.

In Table 5, the facets daily life activities $(r=-0.83)(p \leq$ $.0001)$, labor capability $(r=-0.77)(p \leq .0001)$, sleep and rest $(r=-0.72)(p \leq .0001)$, which are part of physical dimension are related with intestinal ostomized average score, resulting on a loss of perception about QoL on the dimension mentioned above. The seek for daily activities is an aspiration for intestinal ostomized, however, it is opposed with the arousal of expectations such as physical limitation or loss of labor capability and social utility, which discourage them as soon as they find resistance on labor field. Considering this, labor activities help designing essential facets for human life, awakening health variables for physical wealth. This way, labor enhances the individual as someone inserted into society. ${ }^{[5]}$

Concerning the facet sleep and rest, a negative relation with participants' QoL was observed. This result is in accordance with a previous study describing interruptions on ostomized patients sleep, showing relation with physical capability scale. Sleeping quality is intrinsically related to peoples' routine; the lack of sleeping hours may cause health damage, hindering the reposition of energy consumed on daily activity, raising the perception of exhaustion and physical and mental fatigue. ${ }^{[5,14]}$

There is a study on literature showing that fatigue feeling and vigor reduction are considerably enhanced when there is a deficit comprising six hours or less of total sleeping time. It also shows a significant statistic linear trend to raise the intensity of such disturbs, as the number of lost sleeping hours raises. ${ }^{[4]}$ 
Thus, ostomized groups analysis, especially concerning temporary ones was seen as negative regarding sleep and rest. As a consequence, ostomized patients show difficulty on their daily life activities, as well as on their labor capability, which interferes on their physical condition.

Results presented in Table 6 on psychological dimension showed that the facet spirituality, religion, personal beliefs $(r=0.78)(p \leq .0001)$, represented the facet most strongly connected to QoL average score on this dimension. Religion is seen as a spiritual support, providing structure and hope for facing adverse and conflicting situations. Ostomized patients mentioned that they looked for help on a superior being to give them strength and hope to face difficult situations. In general, they looked for God's support in several moments to go through difficult situations they had, after being given the news they would need an intestinal ostomy.

It shows evidence that faith, or searching for heaven help make people seek for resources to face daily fight. The act of getting closer to God gives strength to bear adversities. Then, ostomized patients seek on religiosity, religion, and personal beliefs strength to overcome obstacles, trying to face their condition as ostomized from a more positive point of view.

Regarding the facets, body image, appearance, and selfesteem, respectively, $(r=-0.77)(p \leq .0001),(r=-0.74)$ $(p \leq .0001)$, they affect negatively patients' perception about QoL. It is understandable that an ostomized person experiences psychological changes, as well as social, physical, and spiritual ones, and they see their body image distorted, leading to low self-esteem. Especially because the presence of a hole on their abdomen, from where stools are eliminated, breaks the previous pattern settled in childhood, of will control and domination, privacy and autonomy. ${ }^{[21,22]}$

Thus, as mentioned in advance, the intestinal ostomy procedure leads to events that transform patient's daily life. Such changes, perceived by the ostomized patient, emerge from the loss of a highly valued organ to reduction of self-esteem, as well as a change in body image. Through body image, individual's keep their own inner balance while interacting with the world, and its modification may influence their labor capabilities and their social performance. ${ }^{[6,22]}$

Results shown in Table 7 confirm that the facets personal relations $(r=-0.74)(p \leq .0001)$, sexual activity $(r=-0.76)$ $(p \leq .0001)$, and social support $(r=0.77)(p \leq .0001)$, have a very strong relation with the average score acquired on social relations dimension. However, the facets personal relations and sexual activity affect negatively the perception of QoL on social relations dimension.

Another change coming with intestinal ostomy refers to the individual role and social status in family and society. Regarding the return to an occupational/productive activity, a difficulty of reinsertion for these people was observed due to the loss or limitation of the productive capability observed by the ostomized patient. ${ }^{[3,5]}$

Actually, these are expected events, considering that it is not only from the aesthetical point of view that social interaction is negatively influenced, since losing some part of their body is as traumatizing as losing their autonomy.

As a consequence, social, familiar and labor reinsertion must be this patient's follow-up aim, as well as dealing with leisure activities. It is well-known that these patients face strong difficulty to recover their former sports habits, as well their vacation trips, due to their new condition and the fear of finding themselves into embarrassing situations. However, dealing with possible accidents with collection equipment must be a working strategy for health professionals following those patients, in order to provide elements to offer them a less restricted life, within their physiological conditions. ${ }^{[4,23]}$

QoL is significantly hindered for both genders due to the surgery itself, which may also cause dysuria, pain during sexual intercourse, urinary incontinence or libido loss. ${ }^{[5,24]}$ Furthermore, it interferes on emotional aspects, such as worrying with their partner's acceptance and satisfaction, and it generates a reduced sense of hygiene. This way, changes ocurrying on ostomized people's sexuality are so deep and mutilating that sexual intercourse becomes something secondary and, in general, it is substituted by feelings of love, care, respect, and partnership. ${ }^{[5,24,25]}$

The facet social support reveals the importance of social support started by family. Family support becomes something crucial, as ostomized people present clinical condition undermined by their basic pathology and mutilating surgery, as well as they need specific care with their equipment. Family, as well as friends, provide social protection, which is recognized for playing an essential role in the process involving constitution, development, crisis, and health problems solving. ${ }^{[4,6]}$

Above all, the therapeutic communication set between professionals and ostomized patients and their families, showing engagement to confidence ties and concerns about serving, considering their singularity identifying internal and social resources, which makes this service individualized and helps solving problems and difficulties faced by patients and family. ${ }^{[4,26]}$

Results in Table 8 indicated weaker relation values for the dimension environment, when compared to other dimensions. The same trend was observed in a previous study that had 
shown lower relations for this dimension, justifying that, although all items included in this dimension are related to environment, they are not necessarily intrinsically interrelated. ${ }^{[5]}$

Thus, the most correlated facets were social and health care: availability and quality $(r=-0.76)(p \leq .0001)$, and opportunity to acquire new skills and info $(r=-0.74)(p \leq .0001)$ The referred correlation states that health services organized and oriented for comprehensive assistance tend to be more efficient in responding to patients and families demands. ${ }^{[5]}$

It is worth to mention that health assistance carried out on its three attention levels requires more integration, improving access and directing to problem solving, as well as assuring post-treatment care. Thus, ostomized patients need specialized ambulatory care, requiring adequate equipments and clinical assessment, which provides the maintenance of healthy conditions and the seek for patient's rehabilitation and social reinsertion. ${ }^{[4]}$

Furthermore, integral health assistance for the ostomized is focused on rehabilitation, being the main challenge for the multidisciplinary crew. The approach of these individuals demands a day-to-day reflection towards the different ways of an ostomized person. As such, the estomized person needs special assistance due to its specificities, making the knowledge highly invaluable as well as highly dynamic. ${ }^{[4,13,21,23]}$

On this scenario, the knowledge of QoL perception, as well as the biopsychosocial reality is the main tool for working on the recovery of QoL on ostomized person. Therefore, that knowledge can be applied to schedule preventive actions, identification of special needs as well as establishing priorities for the caring professional, aiming to provide integral health care and QoL recovery. ${ }^{[13,21]}$

Thus, the nursing care process becomes an active and continuous act demanding special actions and behaviors targeting

\section{REFERENCES}

[1] World Health Organization. The WHOQOL Group. Quality of life assessment (WHOQOL): position paper from the World Health Organization. Soc Sci Med. 1995; 41(10): 1403-1409. http://dx.d oi.org/10.1016/0277-9536 (95) 00112-K

[2] Mahjoubi B, Mirzaei R, Azizi R, et al. A cross-sectional survey of quality of life in colostomates: a report from Iran. Health Qual Life Outcomes. 2012; 10(1): 1-6.

[3] Kimura CA, Kamada I, Guilhem D. Quality of life of individual ostomy due oncological reasons: na approach of integrality from Brazilian Unified Health System. Journal of Coloproctology. 2016; 36(1): 34-39. http://dx.doi.org/10.1016/j.jcol.2015.12.003 the improvement of human potentials, focusing on enhancing the dignity of the ostomized person, for which the nursing care process is fundamental for recovering the QoL scores to better and higher levels. ${ }^{[4,13,21,24]}$

Such facts make it possible to comprehend the importance of nursing care in the multidisciplinary crew, and its importance as the beacon for implementing continuous improvement in quality for the ostomized person, as well as its family and community, raising awareness of the importance of nursing care and the performance of the professionals involved in this field regarding these services. ${ }^{[4,13,21]}$

\section{Conclusions}

We understand, then, that actions for education in health for ostomized patients are possible, starting from listening carefully to which sense patients attribute to their new condition. Care must be also extended to family, who are coparticipants on the treatment process, in order to make them support the ostomized in their search for new paths and new life projects. This way, the caring procedures of the multidisciplinary crew, especially nursery staff, deserves reflection, as it implies practical and dialogical knowledge, which must trigger a critical- reflexive attitude towards the meanings of their health procedures, in order to rebuild health practice.

This way, it is possible to understand the relationship between the facets and their respective QoL dimensions of intestinal ostomized patients. Thus, this allows health professionals, especially nurses to design prophylactic procedures, identify needs, and establish action priorities. Awareness about this reality may result in effective and comprehensive health assistance to ostomized patients, leading to their consequent life quality improvement, resulting on a caring process in health and nursing.

\section{CONFlicts of InTERest Disclosure}

The authors declare that there is no conflict of interest.
[4] Kimura CA. Qualidade de vida de pacientes oncológicos estomizados [Quality of life in oncology ostomy patients]. Dissertação (Mestrado em Enfermagem) - Universidade de Brasilia. 2013.

[5] Kimura CA, Kamada I, Jesus CAC, et al. Quality of Life of Colorectal Cancer Patients with Intestinal Stomas. Journal of Carcinogenesis \& Mutagenesis. 2014; 5: 1-7.

[6] Kimura CA, Kamada I, Guilhem D, et al. Quality of life analysis in ostomized colorectal cancer patients. Journal of Coloproctology. 2013; 33(4): 216-221. http://dx.doi.org/10.1016/j.jcol. 2013.08.007

[7] The WHOQOL Group. The World Health Organization quality of life assessment (WHOQOL): development and general psycho- 
metric properties. Soc Sci Med. 1998; 46(12): 1569-85. http: //dx.doi.org/10.1016/S0277-9536(98)00009-4

[8] Brazil. Ministry of Heatlh. Nationald Health Council. Resolution N.466/2012. Guidelines and reguling norms for research involving human subjects. Brasilia: CNS; 2012. Available from: http://co nselho.saude.gov.br/resolucoes/1996/Res196_en.pdf

[9] Fleck MPA, Louzada S, Xavier M, et al. Aplicação da versão em português do instrumento abreviado de avaliação da qualidade de vida "WHOQOL-bref" [Portuguese Version of bref evaluation instrument for quality of life]. Rev Saúde Pública. 2000; 34 (2): 17883. PMid:10881154 http://dx.doi.org/10.1590/S0034-891 02000000200012

[10] Organização Mundial da Saúde (OMS): Relatório do Departamento de Prevenção de Violências, Injúrias e Deficiências. 2013[ Violence, Injury and Handicap Prevention Department]. Disponível em http://www. saude.gov.br. 2012.

[11] Cyrillo RMZ, DalriMCB, Canini SRMS, et al. Diagnósticos de enfermagem em vítimas de trauma atendidas em um serviço pré-hospitalar avançado móvel [Nursing Diagnosis in trauma victims attendance by Advanced EMT mobile unit]. Rev. Eletr. Enf. 2009; 11(4): 811-9. http://dx.doi.org/10.1590/S0034-89102000000200012

[12] Menezes LCG, Guedes MVC, Oliveira RM, et al. Prática de autocuidado de estomizados: contribuições da Teoria Orem [Self care in ostomy patients: contribuitions to Orem Theory]. Rev Rene. 2013; 14(2): 301-310.

[13] Kimura CA, Kamada I, Fortes RC, et al. Reflexões para os profissionais de saúde sobre a qualidade de vida de pacientes oncológicos estomizados [ Reflections for Health Professionals regarding Quality of Life]. Com. Ciências Saúde. 2009; 20(4): 333-340.

[14] Dabirian A, Yaghmaei F, Rassouli M, et al. Quality of life in ostomy patients: a qualitative study. Patient Prefer Adherence. 2011; 5: 1-5.

[15] Stumm EMF, Oliveira ERA, Kirschner RM. Perfil de pacientes ostomizados [ Ostomy Patient Profiles]. Sci. Med. 2008; 18(1): 26-30.

[16] Fortes RC, Monteiro TMTC, Kimura CA. Quality of life from oncological patients with definitive and temporary colostomy. J Coloproctol. 2012; 32(3): 253-259. http://dx.doi.org/10.1590/S2237 $-93632012000300008$

[17] Freitas LR, Garcia LP. Evolução da prevalência do diabetes e deste associado à hipertensão arterial no Brasil: análise da Pesquisa Na- cional por Amostra de Domicílios, 1998, 2003 e 2008 [ Diabetes Prevalence Evolution and its association to High Blood Pressure in Brasil: National Resarch for residence sampling Analysis. Epidemiol. Serv. Saúde. 2012; 21(1): 7-19.

[18] Shaw JE, Sicree RA, Zimmet PZ. Global estimates of the prevalence of diabetes for 2010 and 2030. Diabetes Research and Clinical Practice. 2010; 87 (1): 4-14. PMid:19896746 http://dx.doi .org/10. 1016/j.diabres.2009.10.007

[19] Blumberg RS. Inflammation in the intestinal tract: pathogenesis and treatment. Dig dis. 2009; 27: 455-64. PMid:19897960 http: //dx.doi.org/10.1159/000235851

[20] BATISTA RR, Filho PRR, Castro CAT, et al. Síndrome de Fournier secundária a adenocarcinoma de próstata avançada: relato de caso [ Fournier Syndrome secondary to advanced prostatic adenocarcinoma: Case Report]. Rev Bras Coloproct. 2010; 30 (2): 228-231. http://dx.doi .org/10.1590/S0101-98802010000200016

[21] Nascimento CMS, Trindade GLB, Luz MHBA, et al. Vivência do paciente estomizado: uma contribuição para assistência de enfermagem [Living as a ostomy patiente: A contribuition to nursing assistance]. Texto Contexto de Enfermagem. 2011; 20 (3): 357-64. http://dx.doi.org/10.1590/S0104-07072011000300018

[22] Shabbir J, Britton DC. Stoma complications: a literature overview. Colorectal Disease. 2010; 12 (1): 958-964. PMid:19604288 http: //dx.doi.org/10.1111/j.1463-1318.2009.02006.x

[23] Barbutti RCS, Silva MCP, Abreu MAL. Ostomia, uma difícil adaptação [Ostomy, a hard adaptation]. Revista da SBPH. 2008; 11(2): 27-39.

[24] Kimura CA, Kamada I, Guilhem D, et al. Perception of sexual activities and the care process in ostomized women. Journal of Coloproctology. 2013; 33(3): 145-150. http://dx.doi.org/10.1016 $/ j \cdot j \mathrm{jcol} .2013 .05 .004$

[25] Silva AL, Faustino AM, Oliveira PG. A sexualidade do paciente com estomia intestinal: revisão de literatura [ Intestinal Ostomy Patient Sex life: Review] . Rev enferm, UFPE on line. 2013; 7 (1): 879-887.

[26] Souza PCM, Costa VRM, Maruyama SAT, et al. As repercussões de viver com uma colostomia temporária nos corpos: individual, social e político [The repercutions of living with a temporary ostomy: Individual, Social and Polithics]. Rev Eletr Enf. 2011; 13 (1): 50-9. http://dx.doi.org/10.5216/ree.v13i1.7928 